\title{
Localization of the voltage-dependent sodium channel in the electric eel electrocyte using biotin-labeled scorpion toxin
}

\author{
TaKashi Nakayama and Sonoko Furuya \\ National Institute for Physiological Sciences, Myodaiji, Okazaki 444, Japan
}

\begin{abstract}
A scorpion toxin conjugated with biotin and avidin has been used to investigate the location of the voltage-dependent Na-channel in the electric organ of Electrophorus electricus. Distribution of the conjugated scorpion toxin was visualized under a light or an electron microscope by using biotinylated peroxidase and diaminobenzidine. A dense staining was observed on the innervated surface of the electroplax plasmalemma, but not on the non-innervated surface. Electron micrographs at a higher magnification showed that the caveolar invaginations of the innervated membrane surface were also stained. This specific staining was completely blocked by an excess amount of unmodified scorpion toxin or by a high concentration of $\mathrm{KCl}$ in the incubation medium.
\end{abstract}

The voltage-dependent Na-channel plays an important role in the production of action potential in various excitable cells (11). Na-channel proteins have been purified from the eel electroplax (1), rat brain synaptosomes (10), and from the rat sarcolemma (3). It was shown that a major component of the Na-channel is a polypeptide with a molecular weight of about 250,000 , and also that the purified Na-channel proteins can be incorporated into liposomes without loosing their physiological activity (16-18). Recently, the primary structure of the 250,000 component prepared from the eel electroplax was determined by the cDNA cloning technique (13).

Distribution of the Na-channel in excitable cells was studied immunocytochemically by using polyclonal and monoclonal antibodies raised against the Na-channel from the eel electroplax $(7,8,12)$, and from the rat sarcolemma (9). These studies revealed the characteristic distribution of Na-channels in the electric eel electrocyte $(7,8)$, nodes of Ranvier $(7,9,12)$, and skeletal muscles (9). However, these antibodies are highly species-specific and their cross-reactions are limited. This is due partially to differences in subunit composition of the Na-channel from different excitable membranes.

The polypeptide toxin from the scorpion
Leiurus quinquestriatus binds to the receptor site 3 of the Na-channel with a dissociation constant in $\mathrm{nM}$ range and affect the inactivation process in a highly specific manner $(4,14,15)$. Although binding of scorpion toxin to the Na-channel is reversible and membrane potential-dependent, this interaction occurs in a wide variety of excitable cells. Therefore, scorpion toxin is potentially useful in a comparative study of Na-channel distribution in different species.

Fluorescently labeled or ${ }^{125} \mathrm{I}$-labeled scorpion toxin was used to stain the Na-channel in nodes of Ranvier (2) and in cultured neuronal cells (5). These approaches, however, were not successful in elucidating details of the Na-channel distribution. Recently, biotin-labeled scorpion toxin has been developed with its toxicity unimpaired (6). The biotin-avidin system combined with horseradish peroxidase visualizes the presence of biotinylated ligand at both the light and the electron microscopic level. In the present study, we employed the biotinylated scorpion toxin to demonstrate the location of Na-channels in the electric eel electrocyte.

A crude venom of the scorpion Leiurus quinquestriatus was purchased from Sigma. The toxin $\mathrm{V}$ was purified from the venom according to Okamoto (14). Modification of the purified 

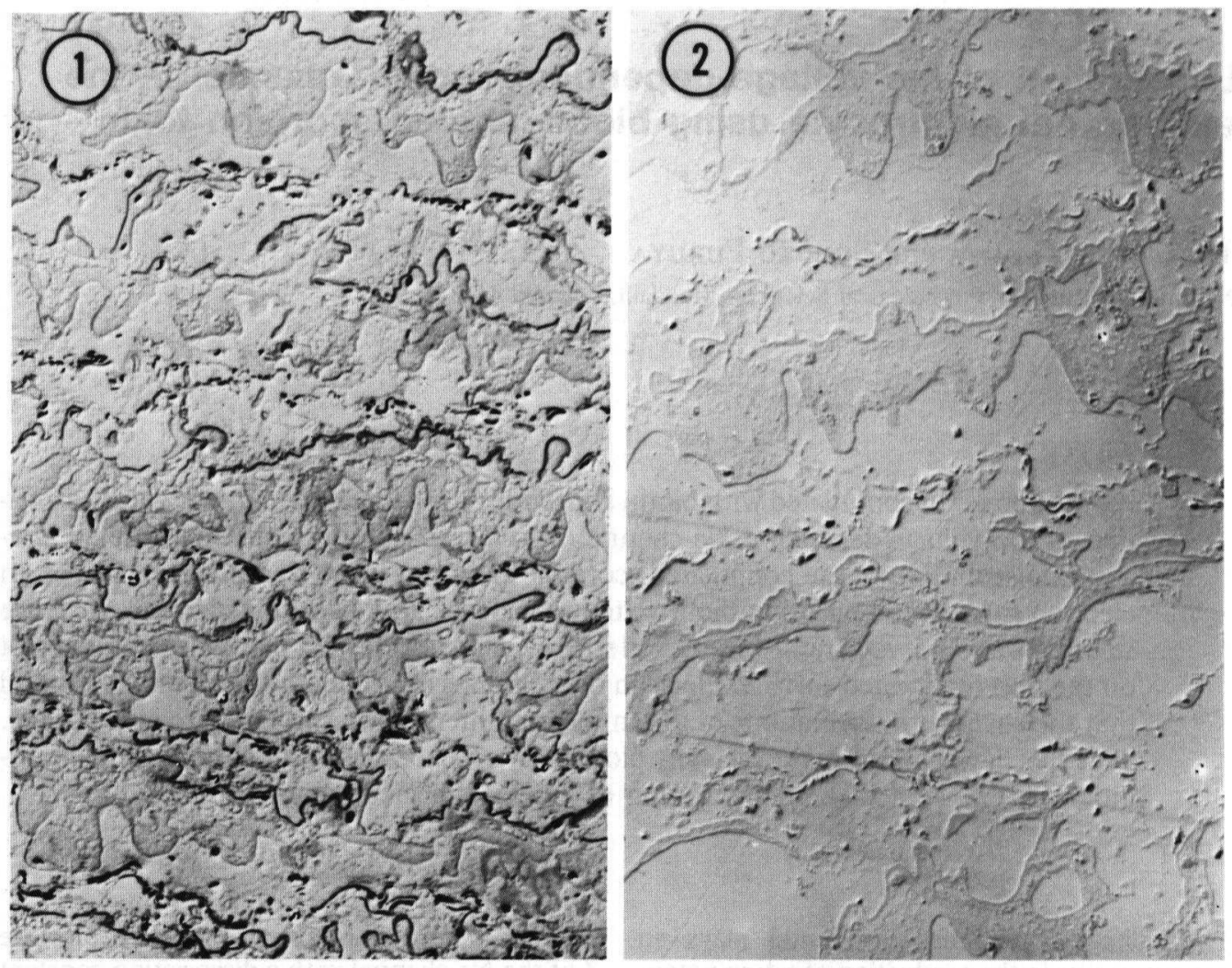

Fig. 1 Light micrograph of the electric eel electrocyte showing a localized distribution of the Na-channel. Unfixed frozen sections prepared from the organ of Sachs were incubated with the biotinylated scorpion toxinavidin complex, and then processed with biotin-labeled peroxidase as described in the text. Reaction products of peroxidase appeared on the innervated surface, but not on the non-innervated surfaces (the convoluted surface) ( $1 \mu \mathrm{m}$ epoxy section). Nomarski optics. $\times 210$

Fig. 2 Control experiment performed in the presence of an excess amount of unmodified scorpion toxin ( $1 \mu \mathrm{m}$ epoxy section). Nomarski optics. $\times 210$

scorpion toxin with biotin- $N$-hydroxysuccimide ester (Pierce) was carried out as described by Darbon et al. (6). After removing the unreacted reagent by gel filtration (Sephadex G-15), the modified scorpion toxin was conjugated with avidin. Non-biotinylated scorpion toxin $\left(M_{\mathrm{r}}\right.$ 7,000 ) was separated from the scorpion toxinbiotin-avidin complex $\left(M_{\mathrm{r}} 75,000\right)$ by gel chromatography (Sephadex G-50). The yield of labeled scorpion toxin was estimated to be about $20 \%$ from the chromatography peak.

A freshly obtained or frozen electric organ was cut into small blocks. They were sliced into sections of $200-400 \mu \mathrm{m}$ in thickness with a microslicer or a cryostat, with their major plane parallel to the long axis of the electroplax. Sections were incubated with the biotinylated scorpion toxinavidin complex $(10 \mathrm{nM})$ for $60 \mathrm{~min}$ at $37^{\circ} \mathrm{C}$ in a solution containing $130 \mathrm{mM}$ choline chloride, $5 \mathrm{mM} \mathrm{KCl}, 1 \mathrm{mM} \mathrm{MgCl}, 5.5 \mathrm{mM}$ glucose, and $20 \mathrm{mM}$ Hepes-Tris (pH 7.4). After incubation, sections were washed several times with ice-cold phosphate-buffered saline (PBS). Then sections were fixed overnight with $2.5 \%$ glutaraldehyde in PBS. The fixed section was washed with ice-cold

Fig. 3 Low magnification electron micrograph of the electrocyte stained with biotinylated scorpion toxin. The difference in staining between the two surfaces of the same cell is evident. $\times 1,670$. Bar, $10 \mu \mathrm{m}$

Fig. 4 Higher magnification electron micrograph of the innervated surface. The Na-channel is distributed uniformly on the membrane, and also on the caveolar invaginations of the innervated membrane surface (arrowheads and inset). $\times 12,900$. Inset, $\times 22,000$. Bar, $1 \mu \mathrm{m}$ 

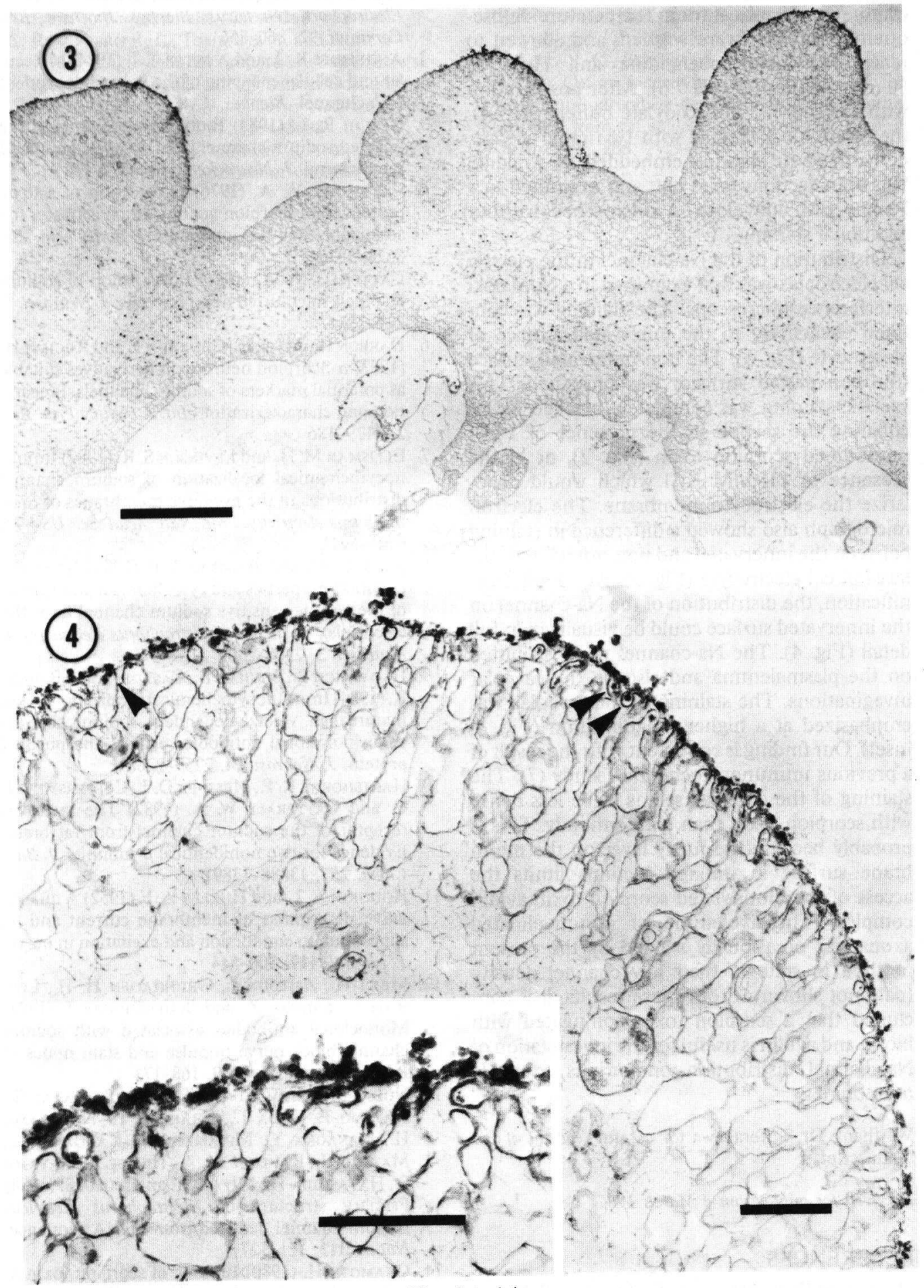

Figs. 3 and 4 
PBS, and incubated with biotin-peroxidase (Sigma) for $30 \mathrm{~min}$ at room temperature. Subsequently, sections were washed, and allowed to react with diaminobenzidine and $\mathrm{H}_{2} \mathrm{O}_{2}$ in $50 \mathrm{mM}$ Tris buffer ( $\mathrm{pH}$ 7.6). After post-fixation with $\mathrm{OsO}_{4}$ in $0.1 \mathrm{M}$ cacodylate buffer ( $\mathrm{pH} 7.4$ ), they were block-stained with $1 \%$ uranyl acetate, dehydrated in ethanol, embedded in Araldite. Ultrathin sections were cut, and examined in a Philips EM 400 electron microscope without additional staining.

Distribution of the Na-channel in the electric eel electroplax was first examined in a Nomarski interference microscope. The staining was confined exclusively to the innervated surface of electrocyte (Fig. 1). The non-innervated surface (the convoluted surface) was unstained. This specific staining was completely blocked by incubating the section in the presence of $1 \mu \mathrm{M}$ unmodified scorpion toxin (Fig. 2), or in the presence of $135 \mathrm{mM} \mathrm{KCl}$ which would depolarize the electrocyte membrane. The electron micrograph also showed a difference in staining between the innervated and non-innervated surfaces of eel electrocyte (Fig. 3). At a high magnification, the distribution of the Na-channel on the innervated surface could be visualized in full detail (Fig. 4). The Na-channel was distributed on the plasmalemma and also on the caveolar invaginations. The staining of the caveolae was emphasized at a higher magnification (Fig. 4, inset). Our finding is consistent with the result of a previous immunocytochemical study (7). The staining of the caveolae seems to be less dense with scorpion toxin than with antibody. This is probably because the fuzzy layer on the membrane surface in unfixed sections limits the access of the biotinylated scorpion toxin-avidin complex. The axolemma of non-myelinated axons was occasionally stained by the present method in spite of their low channel density (data not shown). From these results, it is concluded that a scorpion toxin conjugated with biotin and avidin is useful for the investigation of Na-channel distribution on various excitable membranes.

We thank Dr S. Terakawa for careful reading of the manuscript.

Received for publication 4 March 1985

\section{REFERENCES}

1. Agnew W. S., Moore A. C., Levinson S. R. and RAFTERY M. A. (1980) Identification of a large molecular weight peptide associated with a tetro- dotoxin binding protein from the electroplax of Electrophorus electricus. Biophys. Biochem. Res. Commun. 92, 860-866

2. Angelides K. J. and Nutter T. J. (1984) Molecular and cellular mapping of the voltage-dependent $\mathrm{Na}^{+}$channel. Biophys. J. 45, 31-34

3. BARCHI R. L. (1983) Protein components of the purified sodium channel from rat skeletal muscle sarcolemma. J. Neurochem. 40, 1377-1385

4. Catterall W. A. (1976) Purification of a toxic protein from scorpion venom which activates the action potential $\mathrm{Na}^{+}$ionophore. J. Biol. Chem. 251, 5528-5536

5. Catterall W. A. (1981) Localization of sodium channels in cultured neuronal cells. J. Neurosci. 1, 777-783

6. Darbon H., Jover E., Couraud F. and Rochat H. (1983) $\alpha$-Scorpion neurotoxin derivatives suitable as potential markers of sodium channels. Preparation and characterization. Int. J. Peptide Prot. Res. 22, 179-186

7. Ellisman M. H. and Levinson S. R. (1982) Immunocytochemical localization of sodium channel distributions in the excitable membranes of Electrophorus electricus. Proc. Natl. Acad. Sci. USA 79, 6707-6711

8. Fritz L. C. and Brockes J. P. (1983) Immunochemical properties and cytochemical localization of the voltage-sensitive sodium channel from the electroplax of the eel (Electrophorus electricus). $J$. Neurosci. 3, 2300-2309

9. Haimovich B., Bonilla E., Casadei J. and Barchi R. (1984) Immunocytochemical localization of the mammalian voltage-dependent sodium channel using polyclonal antibodies against the purified protein. J. Neurosci. 4, 2259-2268

10. Hartshorne R. P., Messner D. J., Coppersmith J. C. and Catterall W. A. (1982) The saxitoxin receptor of the sodium channel from rat brain. Evidence for two nonidentical $\beta$ subunits. J. Biol. Chem. 257, 13888-13891

11. Hodgkin A. L. and Huxley A. F. (1952) A quantitative description of membrane current and its application to conduction and excitation in nerve. J. Physiol. 117, 500-544

12. Meiri H., Zeitoun I., Grunhagen H. H., LeVRam V., EshHar Z. and Schlessinger J. (1984) Monoclonal antibodies associated with sodium channel block nerve impulse and stain nodes of Ranvier. Brain Res. 310, 168-173

13. Noda M., Shimizu S., Tanabe T., Takai T., Kayano T., Ikeda T., Takahashi H., Nakayama H., Kanaoka Y., Minamino N., Kangawa K., Matsuo H., Raftery M. A., Hirose T., Inayama S., Hayashida H., Miyata T. and Numa S. (1984) Primary structure of Electrophorus electricus sodium channel deduced from cDNA sequence. Nature 312, 121-127

14. Окамото Н. (1980) Binding of scorpion toxin to sodium channels in vitro and its modification by $\beta$ bungarotoxin. J. Physiol. 299, 507-520

15. Окамотo H., Takahashi K. and Yamashita $\mathrm{N}$. 
(1977) One-to-one binding of a purified scorpion toxin to Na channels. Nature 266, 465-468

16. Rosenberg R. L., Tomiko S. A. and AGNEW W. S. (1984) Single-channel properties of the reconstituted voltage-regulated $\mathrm{Na}$ channel isolated from the electroplax of Electrophorus electricus. Proc. Natl. Acad. Sci. USA 81, 5594-5598

17. Tamkun M. M., Talvenheimo J. A. and CatterALL W. A. (1984) The sodium channel from rat brain. Reconstitution of neurotoxin-activated ion flux and scorpion toxin binding from purified components. J. Biol. Chem. 259, 1676-1688

18. Tanaka J. C., Eccleston J. F. and Barchi R. L. (1983) Cation selectivity characteristics of the reconstituted voltage-dependent sodium channel purified from rat skeletal muscle sarcolemma. $J$. Biol. Chem. 258, 7519-7526 